\title{
Wpływ podgrzewania wstępnego na właściwości mechaniczne złączy spawanych ze stali X10CrAlSi13
}

\author{
Influence of preheat temperature on mechanical properties \\ of steel X10CrAlSi13 welded joints
}

\section{Streszczenie}

W pracy przedstawiono wyniki badań wpływu podgrzewania wstępnego na właściwości mechaniczne złącza spawanego stali X10CrAlSi13. Badaniu poddano dwa złącza oznaczone jako: P1 i P2, gdzie odpowiednio: nie zastosowano i zastosowano podgrzewanie wstępne. Analiza porównawcza złączy obejmowała badania właściwości mechanicznych, które obejmowały. statyczną próbę rozciągania, pomiar twardości, próbę udarności oraz próbę gięcia. Badania właściwości mechanicznych uzupełniono badaniami makroskopowymi. Dodatkowo została oceniona zasadność stosowania spoiw austenitycznych do spawania tej klasy stali. Wskazano również dalsze kierunki badań nad chromowymi stalami ferrytycznymi.

Słowa kluczowe: podgrzewanie wstępne; chromowa stal ferrytyczne; właściwości mechaniczne

\section{Abstract}

The paper presents influence of preheat temperature on mechanical properties of steel X10CrAISi13 welded joints. Research also includes macrography with evaluation of grain growth and an angle bend test along with assessment of plasticity properties. Additionally austenitic welding consumables were validated in terms of forming weld joint with appropriate properties. Finally study provides guidance for further research on X10CrAlSi13 welded joints.

Keywords: preheat; chromium ferritic steel; mechanical properties

\section{Wstęp}

W przemyśle energetycznym stale ferrytyczne odporne na korozję stanowią konkurencję dla stali austenitycznych, ze względu na ich niższą cenę. Główną wadą stali ferrytycznych jest wysoka temperatura przejścia w stan kruchy, ze względu na dużą ilość chromu zawierającego się w przedziale od $10,5 \%$ do $30 \%$ oraz mniejsza odporność na korozję równomierną w porównaniu do stali austenitycznych. Cechą charakterystyczną tej grupy stali jest mała zawartość węgla oraz brak przemian fazowych, co czyni je stalami niehartującymi się. Warunkiem koniecznym uzyskania zadawalających właściwości mechanicznych i plastycznych stali ferrytycznych jest uzyskanie drobnoziarnistej struktury [1 $\div 4]$. Ograniczeniem w zastosowaniu chromowych stali ferrytycznych jest niespełnienie wymagań dyrektywy ciśnieniowej 97/23/ WE PED dotyczących stali. Dyrektywa ta narzuca energię łamania na poziomie co najmniej $27 \mathrm{~J}$ i wydłużenia wynoszącego minimalnie 14 \% w każdej strefie złącza spawanego.

Chromowa stal ferrytyczna X10CrAISi13 należy do grupy staliżaroodopornychijest przeznaczona na żaroodporne części kotłów (m.in. brodawki pomiarowe, elementy mocujące

Tablica I. Skład chemiczny stali X10CrAISi13

Table I. Chemical composition of X10CrAISi13 steel

\begin{tabular}{|c|c|c|c|c|c|c|c|}
\hline \multicolumn{8}{|c|}{ Zawartość pierwiastków, \% masy } \\
\hline X10CrAISi13 & C & Si & Mn & $\mathbf{P}$ & S & $\mathrm{Cr}$ & Al \\
\hline $\begin{array}{l}\text { Skład chemiczny } \\
\text { badanej stali }\end{array}$ & 0,065 & 0,94 & 0,84 & 0,021 & 0,001 & 12,56 & 0,93 \\
\hline $\begin{array}{c}\text { Wymagana zawar- } \\
\text { tość pierwiastków } \\
\text { według PN-EN } \\
10095\end{array}$ & $\max 0,12$ & $0,50 \div 1,0$ & $\max 1,00$ & $\max 0,040$ & $\max 0,015$ & $12,00 \div 14,00$ & $0,70 \div 1,20$ \\
\hline
\end{tabular}

Mgr inż. Maciej Woszek - Doosan Babcock Energy Polska Sp. z o.o.; dr hab. inż. Jacek Słania, Prof. PCz; dr hab. inż. Grzegorz Golański, Prof. PCz - Politechnika Częstochowska.

Autor korespondencyjny/Corresponding author. maciejwoszek@gmail.com 
Tablica II. Właściwości mechaniczne stali X10CrAlSi13

Table II. Mechanical properties of X10CrAlSi13 steel

\begin{tabular}{|c|c|c|c|c|}
\cline { 2 - 4 } \multicolumn{1}{c|}{} & $\begin{array}{c}\mathbf{R p}_{0,2}, \\
\mathbf{M P a}\end{array}$ & $\begin{array}{c}\mathbf{R}_{\mathbf{m}}, \\
\mathbf{M P a}\end{array}$ & Twardość, HV10 & $\begin{array}{c}\text { Wydłużenie A, } \\
\%\end{array}$ \\
\hline $\begin{array}{c}\text { Właściwości stali } \\
\text { W stanie dostawy }\end{array}$ & 437 & 591 & 192 & 15 \\
\hline $\begin{array}{c}\text { Wymagane właściwości } \\
\text { według PN-EN 10095 }\end{array}$ & $\operatorname{min.250}$ & $450 \div 650$ & $\max 250$ & min. 15 \\
\hline
\end{tabular}

Tablica III. Skład chemiczny, właściwości mechaniczne oraz parametry pracy elektrody FOX A7 Table III. Chemical composition and welding parameters of FOX A7 electrode

\begin{tabular}{|c|c|c|c|c|}
\hline \multicolumn{5}{|c|}{ Zawartość pierwiastków, \% masy } \\
\hline $\mathrm{C}$ & $\mathrm{Si}$ & $\mathrm{Mn}$ & $\mathrm{Cr}$ & $\mathrm{Ni}$ \\
\hline 0,1 & 0,7 & 6,5 & 18,8 & 8,8 \\
\hline \multicolumn{5}{|c|}{ Właściwości mechaniczne } \\
\hline $\mathrm{R}$, & $\mathrm{R}$, & $\mathrm{KV}$ & Parametry pracy \\
\hline $\mathrm{MPa}$ & $\mathrm{MPa}$ & $\mathrm{J}$ & Temperatura pracy \\
\hline 480 & 660 & 38 & 90 & do $850{ }^{\circ} \mathrm{C}$ \\
\hline
\end{tabular}

i szeregujące przegrzewacze) oraz pieców przemysłowych, komór próżniowych itp. Maksymalna temperatura pracy - żaroodporność tej stali wynosi $850^{\circ} \mathrm{C}$. Stal ta jest odporna na działanie gazów zawierających związki siarki i gazy redukujące, słabo odporna na działanie atmosfery nawęglającej, azotującej i węgloazotującej [5].

Spawalność stali X10CrAISi13 jest kompleksowym problemem, ze względu na skład chemiczny z dużą ilością ferrytotwórczych pierwiastków stopowych (Cr, Al, Si), małą plastyczność stali i wrażliwość na przegrzanie powodująca uzyskanie struktury gruboziarnistej $[1,3,4]$. Prawidłowy dobór techniki, parametrów spawania oraz materiałów dodatkowych do spawania jest bardzo istotny ze względu na uzyskanie właściwości mechanicznych i plastycznych spełniających wymagania stawianym konstrukcjom wykonanym ze stali X10CrAISi13.

\section{Materiał do badań}

Materiałem do były płyty o wymiarach 10 × 200 x $125 \mathrm{~mm}$ wykonane ze stali X10CrAISi13. Badany materiał dostarczony był w stanie wyżarzonym. Skład chemiczny oraz właściwości mechaniczne materiału rodzimego w stanie dostawy zestawiono w tablicy I i II.

\section{Technologia spawania}

Ze względu na dane literaturowe $[1,3,4]$ zalecające stosowanie podgrzewania wstępnego na poziomie temperatury $200 \div 300^{\circ} \mathrm{C}$ oraz wyżarzania odprężającego w temperaturze $700 \div 750{ }^{\circ} \mathrm{C}$ opracowane zostały dwa pWPS-y. W pierwszym wykonano złącze doczołowe blach w pozycji PF z podgrzewaniem wstępnym na poziomie $200{ }^{\circ} \mathrm{C}$ i temperaturą międzyściegową wynoszącą $250^{\circ} \mathrm{C}$ (złącze oznaczono jako P2). W drugim również wykonano złącze doczołowe blach w pozycji $P F$, ale bez podgrzewania wstępnego z temperaturą międzyściegową na poziomie $150{ }^{\circ} \mathrm{C}$ (złącze oznaczono jako P1). Zarówno złącze P1, jak i P2 nie zostały poddane obróbce cieplnej po spawaniu. Technologia spawania została zaplanowana w celu zbadania zasadności podgrzewania wstępnego stali X10CrAISi13. Charakterystyka stali ferrytycznych wrażliwych na przegrzanie i doprowadzane ciepło do złącza oraz jednofazowa struktura ferrytyczną nie wskazuje na słuszność zaleceń obróbki cieplnej i podgrzewania wstępnego stali tej klasy.

Złącza wykonano metodą 111 ze względu na dużą wszechstronność metody oraz częste wykonywanie złączy tego typu w warunkach montażowych, gdzie wykorzystanie gazu osłonowego może być problematyczne. Warto zauważyć, że w przypadku spawania metodą 111 tej klasy złączy musi być zapewniony dostęp do złącza z dwóch stron ze względu na konieczności wycięcia/wyszlifowania grani i wykonaniu drugiego lica lub zastosowanie spawania na podkładce $z$ osłoną grani gazem obojętnym.

Materiałem dodatkowym wykorzystanym w obu technologiach była elektroda E 188 Mn B 22 (Böhler FOX A7). Spoiwa austenityczne są zalecane do spawania chromowych stali ferrytycznych ze względu na bardzo dobre właściwości plastyczne, udarność stopiwa oraz podwyższenie odporności na korozję spoiny. Elektroda FOX A7 w pełni spełnia wymagania stawiane materiałowi rodzimemu. Skład chemiczny oraz właściwości mechaniczne elektrody FOX A7 zostały przedstawione w tablicy III.

\section{Badania właściwości mechanicznych}

Badania właściwości mechanicznych obejmowały: pomiar twardości metodą Vickers'a, statyczną próbę rozciągania, próbę udarności oraz próbę gięcia. Badania właściwości mechanicznych zostały przeprowadzone zgodnie z obowiązującymi normami. Uzyskane wyniki badań przedstawiono na rysunkach $1 \div 6$ oraz tablicy IV.

\section{Pomiar twardości}

Dla złącza P1 maksymalna twardość nie przekracza wartości 225 HV10 dla pomiaru od strony grani. Twardość materiału rodzimego (MR) i strefy wpływu ciepła (SWC) była na poziomie nie przekraczającym 190 HV10. Według normy materiałowej PN-EN 10095 materiał rodzimy X10CrAISi13 powinien wykazywać twardość poniżej 250 HV10. Ten warunek został spełniony dla SWC i spoiny złącza P1. Warto jednak zauważyć, iż norma dotycząca kwalifikacji technologii spawania 15614-1 nie stawia wymagań twardości chromowym 
stalom ferrytycznym (grupa materiałowa 7 według ISO TR 15608). W związku z powyższym złącze P1 spełnia wszelkie wymagania stawiane twardości przez normy dotyczące stali X10CrAISi13.

Złącze P2 w którym zostało zastosowane podgrzewanie wstępne na poziomie $200{ }^{\circ} \mathrm{C}$ wykazuje bardzo podobny rozkład twardości do złącza P1. Maksymalna twardość w spoinie, podobnie jak w złączu P1, nie przekracza 225 HV10. Twardość materiału rodzimego i strefy wpływu ciepła nie przekracza wartości 190 HV10. Porównywalna twardość na przekroju złącza P1 i P2 wskazuje, że podgrzewanie wstępne nie miało wpływu na twardość.

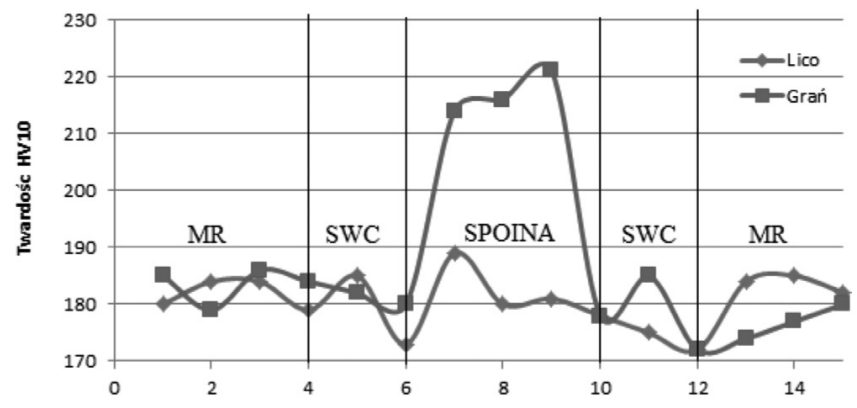

Rys. 1. Rozkład twardości od strony lica i grani w złączu niepodgrzewanym wstępnie $(\mathrm{P} 1)$

Fig. 1. Hardness distribution from toe and root side in weld join without preheat $(\mathrm{P} 1)$

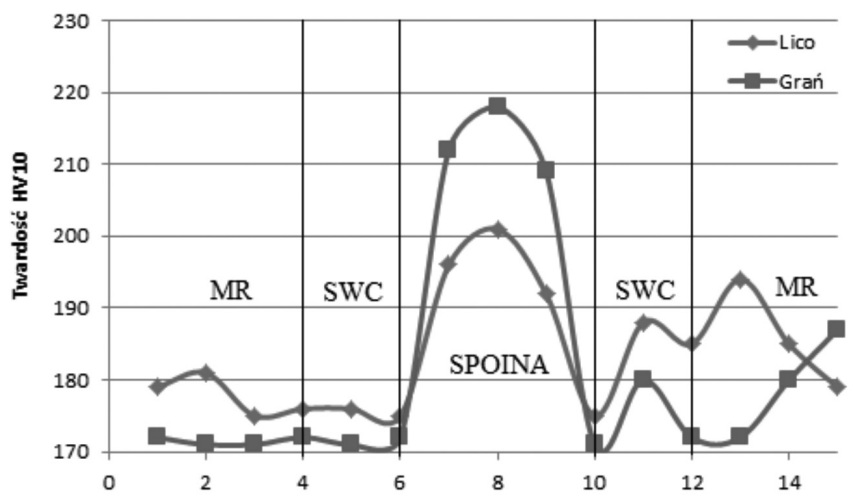

Rys. 2. Rozkład twardości od strony lica i grani w złączu podgrzewanym wstępnie (P2)

Fig. 2. Hardness distribution from toe and root side in preheated weld joint $(\mathrm{P} 1)$

\section{Statyczna próba rozciągania}

Właściwości wytrzymałościowe obu złączy spełniają wymagania normy PN-EN 10095 (tablica II) dla stali X10CrAlSi13. Wytrzymałośc na rozciąganie $\mathrm{Rm}$ dla złącza P1 wynosiła $495 \mathrm{MPa}$, natomiast dla złącza P2: $517 \mathrm{MPa}$ (tablica IV). Uzyskane wartości wytrzymałości na rozciąganie dla złączą P1 i P2 są do siebie zbliżone (różnica jest poniżej 5\%), co wskazuje że zastosowane podgrzewanie wstępne, podobnie jak w przypadku pomiaru twardości, nie miało istotnego wpływu na właściwości wytrzymałościowe złącza ze stali X10CrAlSi13. Zarówno złącze P1, jak i złącze P2 nie spełnia warunków dyrektywy ciśnieniowej 97/23/WE PED wymagającej wydłużenia A na poziomie $\geq 14 \%$.

\section{Próba udarności}

Energia łamania próbek złączy P1 i P2 w analizowanych obszarach są również porównywalne. Strefa wpływu ciepła dla złącza bez podgrzewania wstępnego P1 charakteryzowała się energią łamania na poziomie $16 \mathrm{~J}$, natomiast energia łamania SWC złącza z podgrzewaniem wstępnym P2 wynosiła 18 J. Najwyższą wartością energii łamania charakteryzowała się natomiast spoina, dla której zmierzona wartość energii łamania KV wynosiła ponad $90 \mathrm{~J}$ (rys. 3). Wysoka energia łamania spoiny wynika z zastosowania jako materiału dodatkowego spoiwa austenitycznego, gwarantującego uzyskanie wysokiej ciągliwości. Złącze P2 odznacza się energią łamania nieznacznie większą od złącza niepodgrzewanego $\mathrm{P} 1$. Norma PN - EN 15614-1 oraz PN - EN 10095 nie stawiają określonych wymagań energii łamania stali X10CrAlSi13. Porównywalna wartość energii łamania SWC i MR oraz wysoka energia łamania spoiny świadczy o poprawnie wykonanych złączach. Wyniki potwierdzają również znikomy wpływ podgrzewania wstępnego na uzyskaną wartość energii łamania złącza wykonanego ze stali X10CrAlSi13.

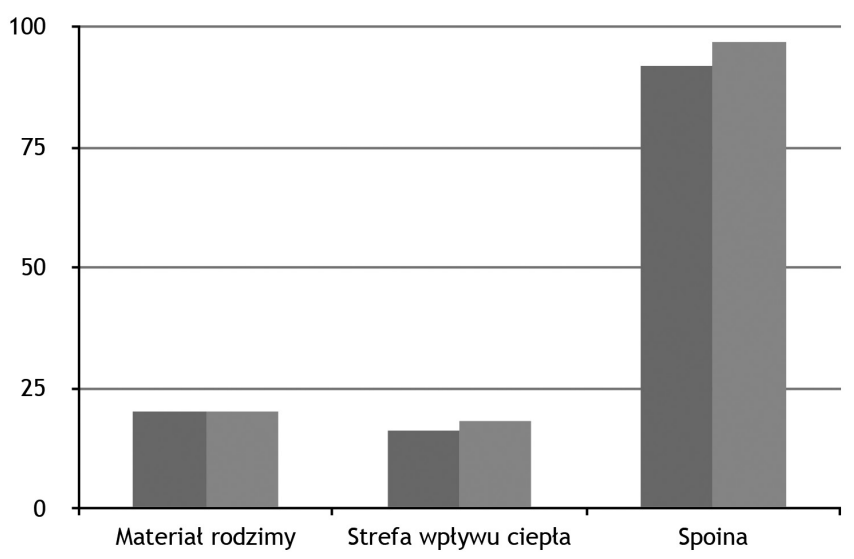

Rys. 3. Średnia wartość energii łamania w różnych strefach złączy P1 i P2 Fig. 3. Impact energy of melt 1 and 2

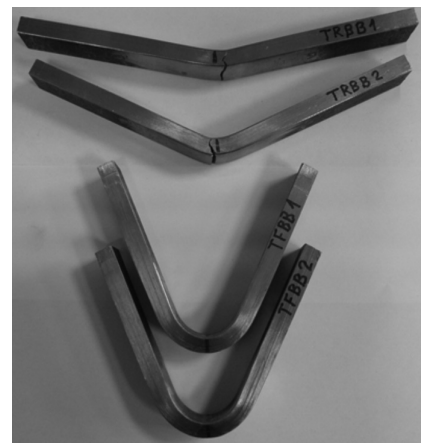

Rys. 4. Wyniki próby gięcia z rozciąganiem lica (TFBB) i grani (TRBB) dla złączy P1 i P2

Fig. 4. Results of angle bend test from toe side (TFBB) and root side (TRBB) for welded joints P1 and P2

Tablica III. Wytrzymałość na rozciąganie badanych złączy

Table III. Ultimate tensile strength of both welded joints

\begin{tabular}{|c|c|c|}
\hline Złącze & $\begin{array}{c}\mathbf{R}_{\mathbf{m}} \\
\text { MPa }\end{array}$ & $\begin{array}{c}\text { A, } \\
\%\end{array}$ \\
\hline P1 & 495 & 10,95 \\
\hline P2 & 517 & 13,4 \\
\hline
\end{tabular}




\section{Próba gięcia}

Próba technologiczna gięcia zakończyła się wynikiem negatywnym zarówno w przypadku złącza P1, jak i dla złącza P2 (rys. 4). Próba gięcia z rozciąganiem lica (TFBB) uzyskała wymagany kąt $180^{\circ}$ zarówno dla złącza P1, jak i P2. Próba gięcia z rozciąganiem grani (TRBB) ujawnia widoczne pęknięcia przez cały przekrój złącza już przy $20^{\circ}$ dla złącza P1 i przy $28^{\circ}$ dla złącza P2. Analizowane złącza otrzymały wynik negatywny podczas próby, lecz warto podkreślić, że próba gięcia nie jest wymagana dla złączy ze stali X10CrAlSi13.

\section{Badania makroskopowe}

Badania makroskopowe przeprowadzone na złączu P1 (Rys. 5) i P2 (Rys. 6) potwierdziły brak niezgodności spawalniczych po badaniach wizualnych VT. Złącza P1 i P2 spełniają kryteria jakości B według PN-EN 5817. Na zdjęciach makrostruktury można zauważyć rozrost ziaren struktury w strefie wpływu ciepła w obydwu złączach, szczególnie w obszarze CGHAZ, czyli strefie struktury przegrzanej.

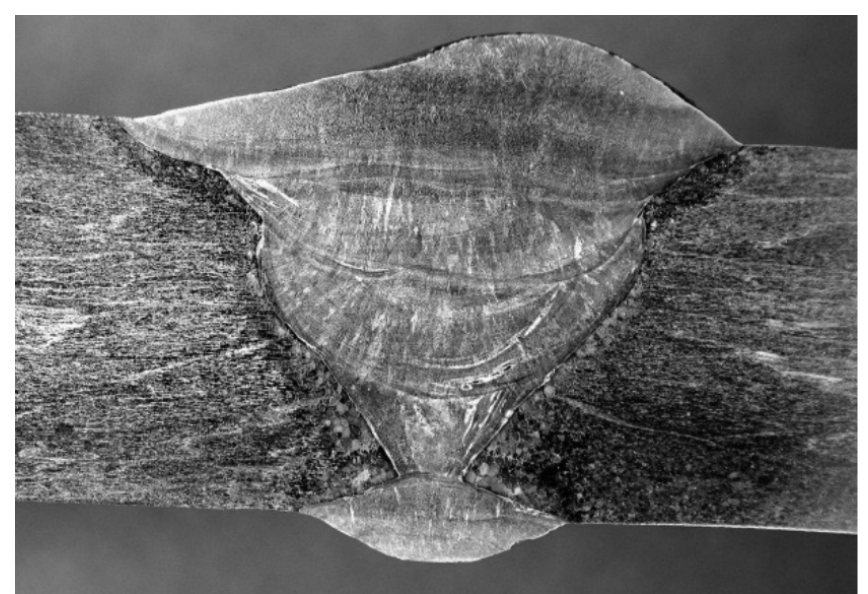

Rys. 5. Makrostruktura złącza bez podgrzewania wstępnego ze stali X10CrAlSi13 (P1). Trawiono chlorek żelaza

Fig. 5. Macrography of X10CrAlSi13 welded join (P1) without preheat

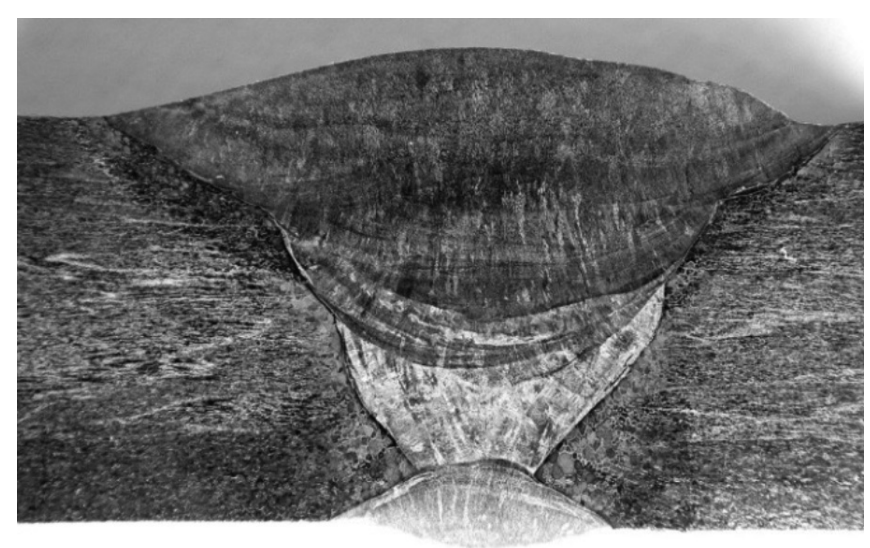

Rys. 6. Makrostruktura złącza ze stali X10CrAlSi13 z podgrzewaniem wstępnym (P2). Trawiono chlorek żelaza

Fig. 6. Macrography of X10CrAISi13 welded join (P2) with preheat

\section{Podsumowanie}

Złącze P1 tj. złącze wykonane bez podgrzewania wstępnego charakteryzowało się właściwościami bardzo zbliżonymi do właściwości złącza P2, które wykonano z podgrzewaniem wstępnym. Wskazuje to na znikomy wpływ podgrzewania wstępnego na właściwości mechaniczne złączy wykonanych ze stali X10CrAlSi13.

Uzyskane wyniki pomiaru twardości dla badanych złączy były na podobnym poziomie ze względu na jednofazową strukturę ferrytyczną stali X10CrAlSi13.

Spoiwo austenityczne jest zalecane dla spawania tej klasy stali ze względu na gwarantowaną wysoką energię łamania $(90 \mathrm{~J})$ oraz spełnienie wymaganych właściwości wytrzymałościowych.

Dalsze badania nad złączami spawanymi stali X10CrAlSi13 powinny obejmować zastosowanie obróbki cieplnej według zaleceń norm, na złączach bez podgrzewania i z zastosowanym podgrzewanym wstępnym.

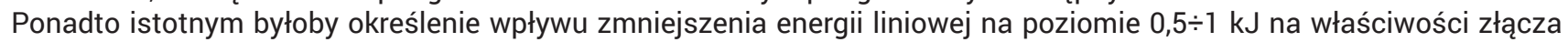
wykonanego ze stali X10CrAISi13.

\section{Literatura}

[1] Tasak E., Ziewiec A.: Spawalność materiałów konstrukcyjnych Tom 1: Spawalność stali. Wydawnictwo JAK, Kraków 2009.

[2] Blicharski M.: Inżynieria Materiałowa stal. WNT wydanie drugie, Warszawa 2012.

[3] Poradnik Inżyniera: Tom 1 Spawalnictwo, pod redakcja prof. dr. hab. Inż. Jana Pilarczyka. Wydawnictwo WNT, Warszawa 2014.
[4] Dobrzański L.A.: Metaloznawstwo i obróbka cieplna stopów metali. Wydawnictwo Politechniki Śląskiej, Gliwice 1993.

[5] Ferenc K.: Spawalnictwo. WNT, Warszawa 2013. 